\title{
SEISMIC LOSS ESTIMATION OF MID-RISE MASONRY INFILLED STEEL FRAME STRUCTURES THROUGH INCREMENTAL DYNAMIC ANALYSIS
}

\author{
A. Nassirpour ${ }^{1 *}$, D. D’Ayala ${ }^{1}$
}

\begin{abstract}
The seismic loss estimation is greatly influenced by the identification of the failure mechanism and distribution of the structures. In case of infilled structures, the final failure mechanism greatly differs to that expected during the design and the analysis stages. This is mainly due to the resultant composite behaviour of the frame and the infill panel, which makes the failure assessment and consequently the loss estimation a challenge. In this study, a numerical investigation has been conducted on the influence of masonry infilled panels on physical structural damages and the associated economic losses, under seismic excitation. The selected index buildings have been simulated following real case typical mid-rise masonry infilled steel frame structures. A realistic simulation of construction details, such as variation of infill material properties, type of connections and built quality have been implemented in the models. The fragility functions have been derived for each model using the outcomes obtained from incremental dynamic analysis (IDA). Moreover, by considering different cases of building distribution, the losses have been estimated following an intensity-based assessment approach. The results indicate that the presence of infill panel have a noticeable influence on the vulnerability of the structure and should not be ignored in loss estimations.
\end{abstract}

Keywords: Seismic Loss Estimation, Masonry Infilled Steel Frame, Incremental Dynamic Analysis (IDA), Fragility Curves

\section{INTRODUCTION}

Steel framed structures, with unreinforced masonry infill panels, make up a considerable proportion of residential buildings in seismically active regions (e.g. Japan, China, Turkey, Iran and California), as well as a substantial amount of the world's governmental and public buildings. Infill panels are widely used as external walls and interior partitions in building, however, they are mainly considered as non-structural elements. The infill panel's presence is commonly not included in the analysis and the design process and their influence is solely considered as permanent loading on beams. Since 1950s many studies concluded that the presence of infill has a significant effect on the strength, stiffness and energy dissipation of the structural system (El-Dakhakhni, 2003). Although recent modern earthquake codes, such as S304.1 (CSA, 2004), SEI 41-06 (ASCE, 2006), NZSEE (2006) and MSJC (2010), present guild lines for designing the infill walls, they deter the designers from reducing seismic action effects or from relying on the beneficial presence of infill walls. Therefore, infills are usually considered as a source of significant over-strength and when subjected to strong earthquake excitation, these structures are at high risk of heavy damage. Such structures can be among the dominant causes of structural failure and casualty (Ellul \& D'Ayala, 2012). Thus, with recent rapid growth in

\footnotetext{
${ }^{1}$ Department of Civil Environmental Geomatic Engineering, University College London, WC1E 6BT London UK

*Corresponding Author a.nassirpour@ucl.ac.uk
} 
construction of such buildings, the vulnerability assessment of them has become an issue of interest for decision makers.

The earthquake loss estimation studies go back to 1971 San Fernando earthquake and since a great number of studies have investigated the earthquake losses by referring to empirical data from past events. Furthermore, tools such as PACT and SELENA have been developed, which are able to estimate the losses based on the given capacity of the buildings. Both tools are capable of generating quantitative estimation of losses following intensity-based, scenario-based or time-based assessment methods. In this study, the vulnerability assessment follows the intensity-based assessment methodology, in which the probable performance is estimated when the building is subjected to a specific earthquake shaking intensity (FEMA P-58, 2012).

By altering the material properties and modelling detailing (e.g. simulating connections), a set of different models have been developed, which are able to represent various construction qualities of the same building class defined by HAZUS (2013). For demand assessment, each model has been analysed following Incremental Dynamic Analysis (Vamvatsikos \& Cornell, 2002) approach and the obtained performance points will be employed to generate numerical fragility functions. Consequently, the effect of variability in structural characteristics and seismic input are accounted and the mentioned uncertainties associated in the fragility prediction are evaluated, along with alteration of damage thresholds. As a result, the fragility curves obtained include variation in construction quality, damage thresholds and seismic demand. The dispersion consists of demand and response, in which the variation of construction quality and damage thresholds are included. Therefore, the variables are not just aleatory variables and some epistemic uncertainty related to modelling techniques, construction details and definition of damage thresholds have been included. Estimating the losses for each of the cases will indicate whether a simplified default model can represent the majority of the cases or each case needs to be evaluated separately.

\section{INDEX BUILDING}

For this study, a site near the capital city of Iran, Tehran, a highly seismic megacity has been selected. Recently a great number of masonry infilled steel frame structures have been constructed in different locations of Iran with moderate to extreme seismic activity, exposing a considerable population to the resulting risk from seismic damage. For instance, referring to the 2004 taxation data, obtained from the Tehran Municipality (TMCSO), steel buildings with masonry infill, consist about $27 \%$ (254'000) of the total number of the city's building inventory. Furthermore, in recent years, motives such as ease and speed of erection and prefabrication, reasonable pricing and relatively higher quality of construction, have attracted more contractors to build steel framed structures.

Representing the discussed buildings, a residential four-storey steel frame, with masonry infilled panels has been chosen near Tehran based on a real case design. The construction method and the structural arrangement are among the most common styles of structures in middle-east region (e.g. Iran, Turkey and Saudi-Arabia). As Tehran is located at a highly seismic area, a peak ground acceleration (PGA) of $0.35 \mathrm{~g}$ (highest value in the code) has been applied for its design. Based on the location's geology, semi-compact soil $\left(360 \mathrm{~m} / \mathrm{s}<\mathrm{V}_{\mathrm{s}, 30}<800 \mathrm{~m} / \mathrm{s}\right)$ condition is chosen, which resembles ground type B of BS EN 1998. Although the current Iranian code $\left(4^{\text {th }}\right.$ 
version) has been updated in November 2014, this building was design following the $3^{\text {rd }}$ version of 2800 Iranian seismic code (version III, issued in 2005 after 2003 Bam earthquake), which is highly identical to UBC-97.

Figure 1 illustrate the building's plan of the first floor, indicating the location and dimensions of beams (IPE), columns (HEB) and bracings. The column sections are given in Table 1 and the beam sections are indicated along the elements in the building's plan. For the bracings a hollow square section with a cross sectional area of $120 \times 120 \mathrm{~mm}^{2}$ is implemented. The building is a dual-system mid-rise, consisting of 5-bays (transversal or y-direction) and 4-frames (longitudinal or $\mathrm{x}$-direction). The building does not have any staircase core to act as a centre of stiffness. Lateral resisting system consists of concentric cross bracings in its transverse direction for all stories and moment resisting frame in its longitudinal direction. Additionally, cross bracings are located at the ground level on both directions as illustrated in the building plan. It should be noted that the building plan is unsymmetrical, this may result in torsional effects.

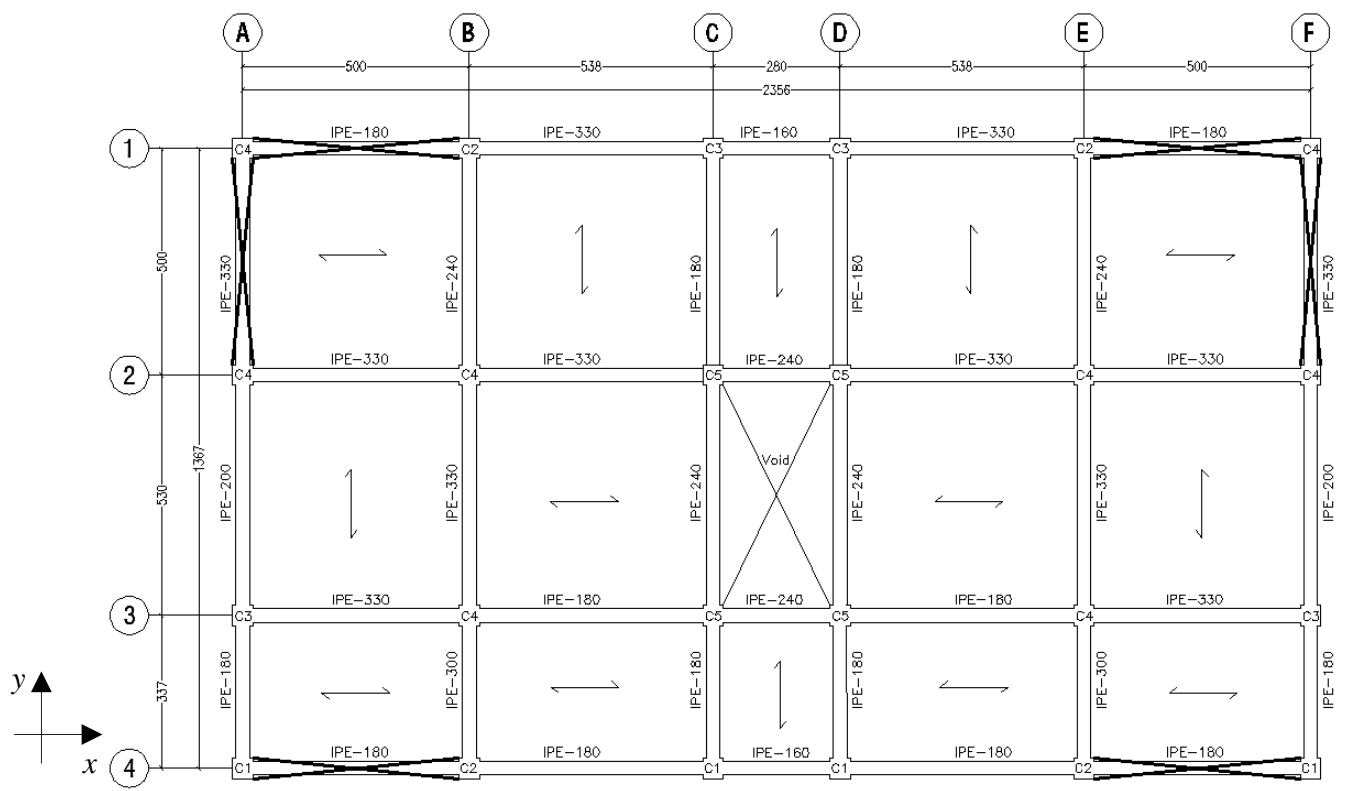

Figure 1 - Plan of the $1^{\text {st }}$ floor of the index building (units in centimetre) IPE: European steel I-beam with parallel flange surfaces

Table 1 - Column sections used for the index building

\begin{tabular}{ccccccc} 
& Columns Ref. & C1 & C2 & C3 & C4 & C5 \\
\cline { 2 - 6 } & $\mathbf{4}^{\text {th }} \boldsymbol{F l o o r}$ & HEB-140 & HEB-140 & HEB-120 & HEB-160 & HEB-160 \\
\cline { 2 - 6 } & $\mathbf{3}^{\text {rd }} \boldsymbol{F l o o r}$ & HEB-140 & HEB-140 & HEB-120 & HEB-160 & HEB-160 \\
\cline { 2 - 6 } & $\mathbf{2}^{\text {nd }} \boldsymbol{F l o o r}$ & HEB-140 & HEB-140 & HEB-140 & HEB-180 & HEB-160 \\
\cline { 2 - 6 } & $\boldsymbol{1}^{\text {st }} \boldsymbol{F l o o r}$ & HEB-140 & HEB-160 & HEB-140 & HEB-180 & HEB-160 \\
\hline
\end{tabular}

\section{Numerical AnAlysis OF MODELS}

Three models with different characteristics have been considered by slightly altering some of the models' characteristics, such as the quality of infill material or the type of connections (e.g. rigid or semi-rigid composite). These are known as the secondary modifier, which do not change the building's class, however they may alter the performance within the structure. 
Model 1 represents the highest quality of all, having a fully rigid beam-column connection and the strongest infill panels (i.e. solid clay bricks). Model 2, has semi-rigid composite connection, which takes in account the effect of the $0.15 \mathrm{~m}$ tick concrete slab and a weaker infill panel (i.e. hollow clay bricks) has been employed. While Model 3 has the same connection and infill as Model 2, it has been assumed that the connections of bracings are not sufficient and they will not contribute to the structural resistance during seismic excitation. For comparative reasons, a bare frame of the index building (Model 4) has also been simulated. This is how most designers and codes consider the buildings to behave. Table 2 summarises the characteristics of each of the mentioned models:

Table 2 - Characteristics of the Models considered

\begin{tabular}{|c|c|c|c|c|c|c|c|}
\hline \multirow{2}{*}{$\begin{array}{c}\text { Model } \\
\text { Ref. }\end{array}$} & \multirow{2}{*}{$\begin{array}{c}\text { Construction } \\
\text { Quality }\end{array}$} & \multicolumn{2}{|c|}{$\begin{array}{c}\text { Infill Strength } \\
{[\mathrm{kPa}]}\end{array}$} & \multirow{2}{*}{$\begin{array}{c}\text { Infill } \\
\text { Modulus } \\
{[\mathrm{MPa}]}\end{array}$} & \multirow{2}{*}{$\begin{array}{c}\text { Infill } \\
\text { Thickness } \\
{[\mathrm{mm}]}\end{array}$} & \multirow[t]{2}{*}{ Connection Type } & \multirow{2}{*}{$\begin{array}{l}\mathbf{T}_{1} \\
{[\mathrm{~s}]}\end{array}$} \\
\hline & & Full & Window & & & & \\
\hline Model 1 & High & $7^{\prime} 400$ & $8^{\prime} 000$ & $5.1 \times 10^{6}$ & 0.11 & Rigid & 0.411 \\
\hline Model 2 & Mid & $6 ' 000$ & 6’000 & $5.8 \times 10^{6}$ & 0.19 & Semi-Rigid & 0.431 \\
\hline Model 3 & Low & 6’000 & $6^{\prime} 000$ & $5.8 \times 10^{6}$ & 0.19 & Semi-Rigid / No Bracing & 0.498 \\
\hline Model 4 & Bare Frame & - & - & - & - & Rigid & 1.327 \\
\hline
\end{tabular}

The building is modelled in three dimensions using fibre based finite element software SeismoStruct (2013). The software is capable of predicting large displacement behaviour of space frames under static and dynamic loadings, taking into consideration the geometric nonlinearities (e.g. P- $\Delta$ and P- $\delta$ ) and material inelasticity. The following discusses the modelling concepts and structural characteristics of each model in more details.

An imposed load of $200 \mathrm{~kg} / \mathrm{m}^{2}$ and $150 \mathrm{~kg} / \mathrm{m}^{2}$ is considered for the floors and the roof ( $4^{\text {th }}$ floor) respectively. The permanent loading consists of floor finishing, joists and metal decks and is estimated equal to $350 \mathrm{~kg} / \mathrm{m}^{2}$ for all floors and $380 \mathrm{~kg} / \mathrm{m}^{2}$ for the roof ( $4^{\text {th }}$ floor).

The steel material modelled is $\mathrm{S} 235$ based on European standards $\left(\mathrm{f}_{\mathrm{y}}=235 \mathrm{MPa}, \mathrm{E}=2.1 \times 10^{5} \mathrm{MPa}\right.$, $\gamma=78 \mathrm{kN} / \mathrm{m}^{3}$ ), which follows a uniaxial bilinear stress-strain model with kinematic strain hardening and applied following Menegotto-Pinto steel model (Menegotto \& Pinto, 1973). This is the most common steel material used for the residential construction practices in the region under study.

The considered column-beam connections, as mentioned, are either rigid or semi-rigid. In order to simulate their behaviour, a total of 96 link elements have been defined at the connection joints. The link elements connect two initially coincident structural nodes and require the definition of an independent force-displacement (or moment-rotation) response curve for each of its local six degrees-of-freedom system (i.e. F1, F2, F3, M1, M2, M3). An idealised asymmetric elasticplastic behaviour, with isotropic hardening rule has been selected to represent the behaviour of each link. The properties of the monotonic moment-rotation (force-displacement) idealised curve were defined according to ASCE and Leon \& Bazzurro (2007). Figure 2 and 3, illustrate a sample of idealised curve and the selected connection detailing. 


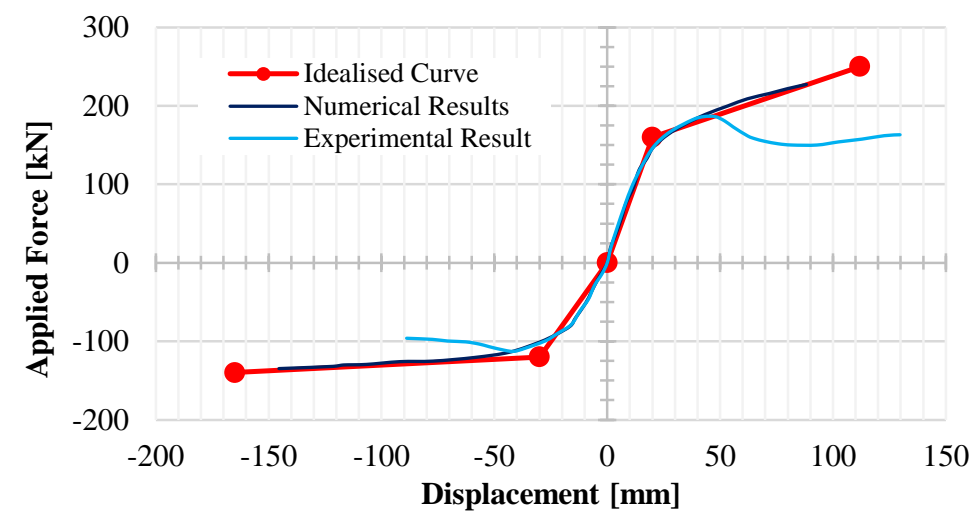

Figure 2 - Idealised curve applied for simulation of semi-rigid composite connection links

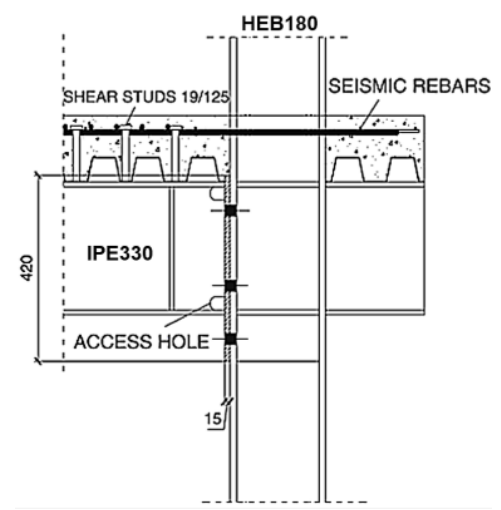

Figure 3 - Detailed sample semi-rigid composite connection with metal deck

As mentioned, commonly, in the structural analysis and design stages, the influence of masonry infills is fully ignored and their presence is simply considered as permanent loading. The main reasons are due to complexity of infill reaction (mechanical property of material and construction detailing), the inherent uncertainty associated to the numerous parameters that behaviour of infills depends on and finally the type of interaction between the infill and it surrounding frame. By comparing the performance of structures with and without the infill panels, it is evident that the presence of infill has a significant effect on the lateral stiffness, strength and ductility of the entire structural system and ignoring it would be hazardous. The infill panels stiffen and strengthen the building significantly at relatively early drift stages. Though, after passing the ultimate strength, a rapid strength drop can be observed due to failure of the panels (Nassirpour \& D'Ayala, 2014). This sudden decrease is problematic and has a significant effect on the resultant seismic losses. Therefore, the influence of infill panels should be considered in the numerical models and consequently their effect should be evaluated in the fragility functions.

On the other hand, the infilled frame structures need a realistic model and cannot be modelled as elasto-plastic system due to the stiffness and strength degradation especially in short period structures in which the hysteresis loops and energy dissipation capacity have a strong influence on the response. Based on empirical results, the lateral resistance of an infilled frame can increase between 4 to 20 times the stiffness of a simple bare frame. Furthermore, the location and the dimensions of openings play an important role in the strength and lateral stiffness of single panels and consequently the whole structural system.

Hence, following the equivalent strut approach, a numerical macro model proposed by Crisafulli (1997) is adopted for simulating the solid infills and those with openings. The adopted doublestrut model, is accurate enough to consider the lateral stiffness and the strength of the masonry, particularly when a shear failure along mortar joints or diagonal tension failure is expected. A drawback of the model is its lack of capability to predict properly the bending moment and shear forces in the surrounding frame, since the panel is connected to the beam-column joints of the frame. However, in this regards, limited cases of shear failure in the steel frame have been observed and in most cases the infill panel fails before the steel frame. Moreover, this analytical model is capable of simulating the most common types of masonry panel failures, known as shear failure and diagonal tension failure. It should be noticed that although the model is also 
capable of considering the out-of-plane failure of infill walls, it has been ignored in this study as it is unlikely due to the arching mechanism.

The masonry infill models have been calibrated with the identical material used in construction of the index building under study. Experimental research conducted by Tasnimi \& Mohebkhah (2011) and Flanagan \& Bennett (1999) on the behaviour of brick-infilled steel frame with and without opening have been selected. The materials used for the pseudo-dynamic tests are of great similarly to those available and commonly used for in construction.

Representing the weak infill panels, nominal $200 \times 300 \times 300 \mathrm{~mm}$ structural hollow clay tile units and type $\mathrm{N}$ (compressive strength $6.2 \mathrm{~N} / \mathrm{mm}^{2}$ ) masonry cement mortar (ASTM C-91) have been chosen. The clay tiles were laid with their cores horizontal (side construction) using approximately $19 \mathrm{~mm}$ full bed joints, and face shell mortar in the head joints. The stronger panel, consists of $219 \times 110 \times 66 \mathrm{~mm}$ solid clay bricks (with no voids) placed in running bond with Portland cement type 1 and sand mortar. The average prism compressive strength of each infill panel has been evaluated following ASTM C-1314 and C-10. For each case a full solid infill and one with large window opening located at its centre (ratio=0.176) have been calibrated with experimental results. For calibration, single-storey, single-bay steel frame specimens were tested under in-plane cyclic loading applied at the top corner of the frame. Therefore, the model is set to be as realistic as possible by considering the location of masonry infills, lateral stiffness, strength of the elements and the effect of any opening (door and windows) on the panels.

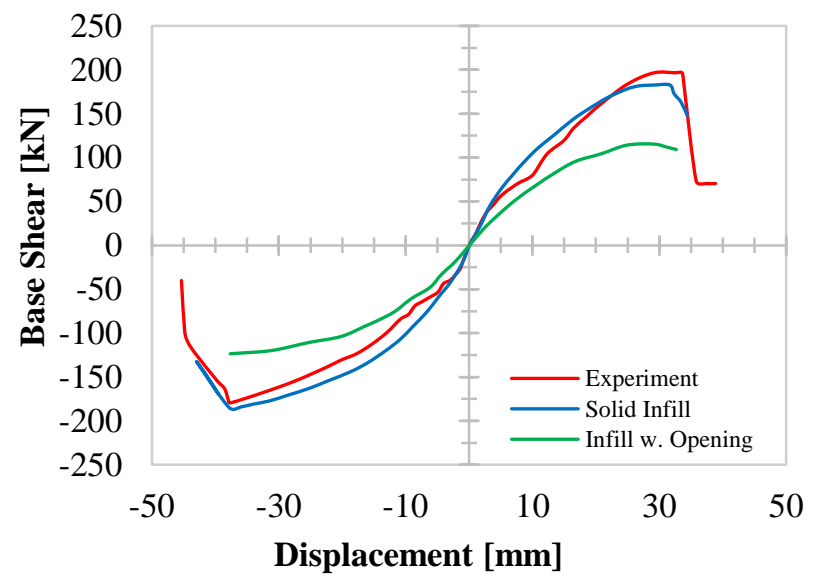

Figure 4 - Backbone curves showing calibration of solid and with window opening infills (Flanagan \& Bennett, 1999) 


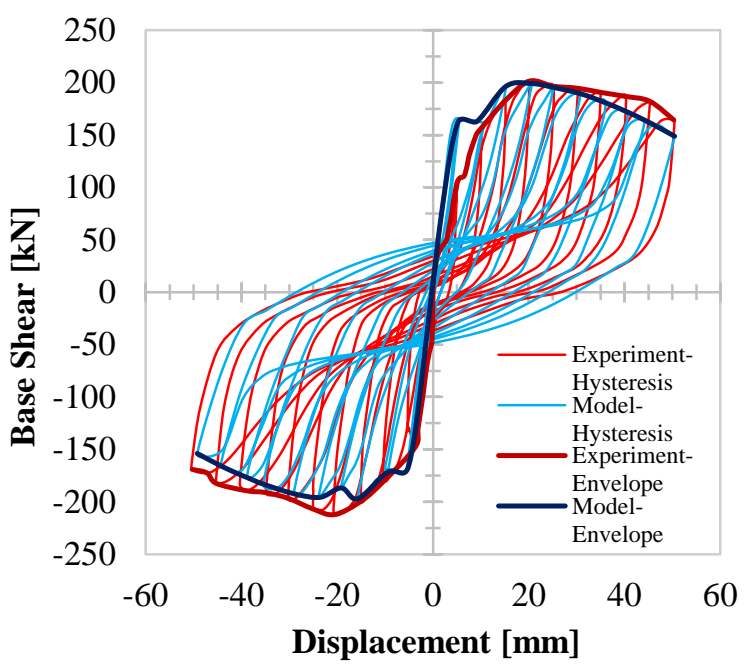

Figure 5 - Backbone and Hysteresis curves showing calibration of solid infill

(Tasnimi \& Mohebkhah, 2011)

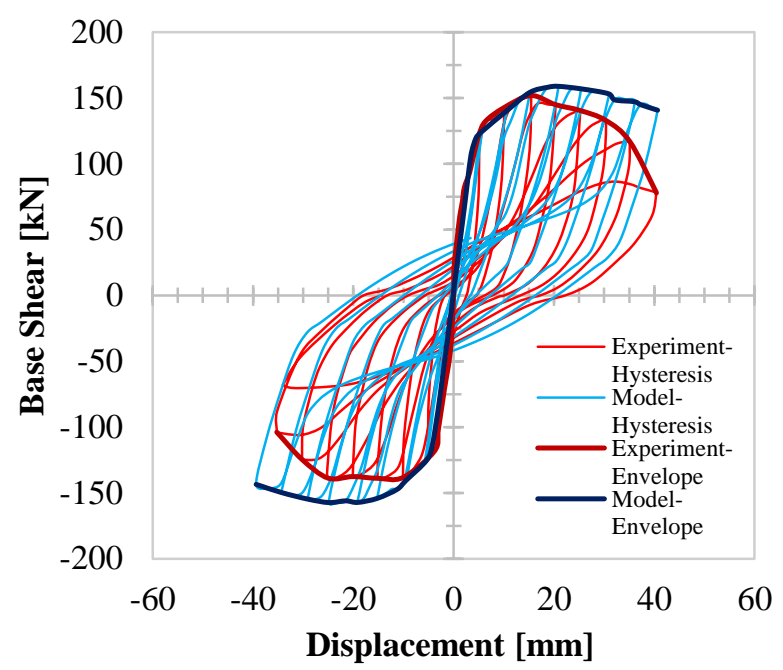

Figure 6 - Backbone and Hysteresis curves showing calibration of infill with window opening (Tasnimi \& Mohebkhah, 2011)

\section{Damage Limit States}

For developing the fragility curves it is necessary to assign rational "Damage States" for each of the structural elements. Therefore, the damage states defined in HAZUS-MH MR5 (2001), ASCE- 41 (2013) and FEMA 356 (2000) have been considered. Furthermore, as three of the analysed buildings, have a composite structural system, where the initial lateral resistance is provided by the masonry infill walls, the damage thresholds have been defined based on the experimental damage observations of Tasnimi \& Mohebkhah (2011) and Flanagan \& Bennett (1999). Accordingly, four levels of slight, moderate, extensive and complete (collapse) structural damage have been defined for the overall damage of the building based on the performance level of the structure subjected to a given earthquake intensity and defined as follows:

1) Slight: hairline cracks (diagonal or horizontal) appear on some of the infill walls, some bricks near the beam-column interaction start to break and crush.

2) Moderate: large cracks (diagonal or horizontal) on most infill walls, a number of bricks dislodged and fall, partial and full collapse of few walls, some walls may bulge out-ofplane, failure at some steel connections, as some critical members may fail, and the structure might undergo a permanent lateral deformation.

3) Extensive: total failure of many infill walls and loss of stability of steel frame, bracings and moment connections start to fail, some infill walls may bulge out-of-plane, consequently the structure loses its lateral resistance. Some steel frame connections may have failed. Structure may exhibit permanent lateral deformation or partial collapse due to failure of some critical members.

4) Complete: structural collapse in which all infill panels disintegrate resulting in compression failure of the masonry struts and the steel frame has lost its stability completely, resulting in an imminent or immediate structural collapse.

In order to refer the mentioned damage states to the global structural behaviour, maximum peak inter-story drift ratio (MIDR) has been employed. This mean of measurement is known to relate 
well to global dynamic instability and several structural performance limit-states (FEMA 354) and a decent engineering demand parameter (EDP) for derivation of fragility functions. Shear capacity can also be a good indicator of the damage in infill panel, however as the structures consist of steel frames and masonry panels, then the selected EDP should be functional for both cases.

The MIDR values used for the fragility analysis are given in Table 3. For this purpose, exceedance of the selected damage index from the corresponding value associated with each of these performance levels indicates the fragility of the system in that specific performance level. It is evident, that the threshold values drop as the construction quality decreases.

Table 3 - Maximum peak inter-story drift ratio values assigned for each model according to its damage state

\begin{tabular}{|c|c|c|c|c|}
\hline Damage State & High Quality & Mid Quality & Low Quality & Bare Frame \\
\hline Slight & $0.32 \%$ & $0.62 \%$ & $0.50 \%$ & $1.00 \%$ \\
\hline Moderate & $1.78 \%$ & $1.50 \%$ & $1.37 \%$ & $2.41 \%$ \\
\hline Extensive & $3.86 \%$ & $2.66 \%$ & $2.45 \%$ & $3.98 \%$ \\
\hline Complete & $6.00 \%$ & $4.80 \%$ & $4.40 \%$ & $5.60 \%$ \\
\hline
\end{tabular}

Figure 7, illustrates the resultant pushover curves and their corresponding damage thresholds obtained for each of the models. It is evident that even in a static pushover analysis in which the cyclic behaviour is not considered, a substantial difference can be observed in terms of initial stiffness, peak capacity and ductility. As expected the structure's behaviour has improvement with its construction quality, while the fundamental period is not substantially extended. This keeps the buildings in the same category defined by HAZUS. Moreover, the pushover curves suggested by HAZUS-MH MR4 for High code Mid-Rise Steel Moment Frame [S1] and High code Mid-Rise Steel Braced Frame [S2] are shown. It should be noted that HAZUS does not propose any capacity curve parameters, nor thresholds for various damage states, for structures categorised as steel frame with unreinforced masonry infill walls [S5] of any height and seismic design level. Therefore, a direct comparison is not possible, however, for the case of bare steel frame, the analysed pushover curve does not agree with the one suggested by HAZUS for midrise moment resisting frame.

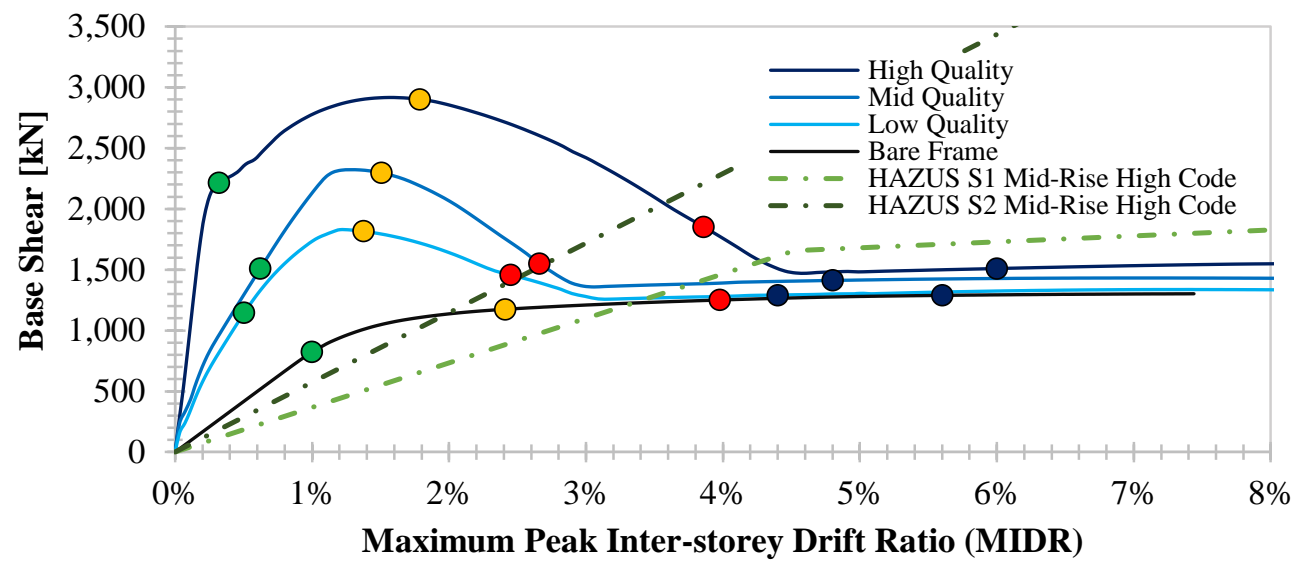

Figure 7 - Pushover curves of analysed models and damage thresholds defined 


\section{GROUND Motion SELECTION}

It is well recognized that nonlinear dynamic analysis is highly sensitive to selected ground motions. Hence, it is essential that the selected set of ground-motion records, reflect the seismic hazard of the site under study and that the scaling of records is legitimate. When these two conditions are not satisfied, a bias in the structural response can occur, however, this can be reduced by careful selection of ground-motions (Baker \& Cornell, 2006; Luco \& Bazzurro, 2007; Shome et al., 1998).

For this study, the far-field ground motion set based on the FEMA P695 has been selected. The suite of ground motions include 22 record pairs, each with two horizontal components for a total of 44 ground motions. The records have a magnitude $\left(\mathrm{M}_{\mathrm{W}}\right)$ range from 6.5 to 7.6 with an average magnitude of $M_{\mathrm{W}} 7.0$ and all were recorded at sites located greater than or equal to $10 \mathrm{~km}$ from the fault rupture. Following the Eurocode 8 Soil classification, 16 sites are classified as stiff soil site and the remaining are classified as very stiff soil. In order to reduce the computational effort, only the component with highest peak ground acceleration has been employed, resulting in to 20 ground motions. Figure 8 illustrates the resultant response spectra of the selected records.
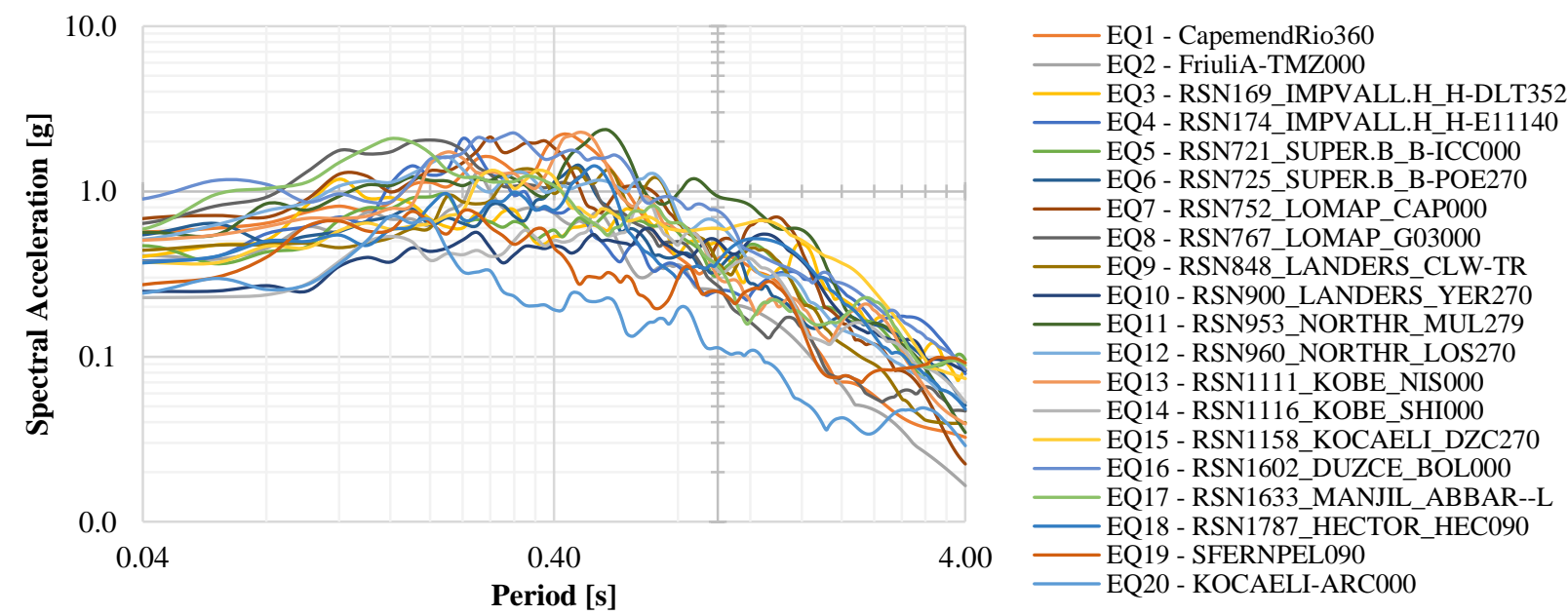

Figure 8 - Response spectra of twenty individual components of the normalised far-field records of FEMA P695

Each record was scaled to distinct spectral acceleration $\left(S_{\mathrm{a}}\right)$ levels, ranging from $0.1 \mathrm{~g}$ to $2.5 \mathrm{~g}$, in increments of $0.1 \mathrm{~g}$ (a total of 25 analyses for each selected record). It is thus an unavoidable fact that the IDA curves display large record-to-record variability, while the record scaling gives the opportunity to cover the entire range of structural response, from elasticity, to yielding and finally collapse. The spectral shape of mentioned ground motions was not a criterion in the selection process, as the FEMA P695 far-field ground motion set are independent of site hazard or structural type. Therefore, the applied records are not reliant on period, any building-specific property of the structure and hazard disaggregation.

\section{Nonlinear Dynamic Analysis Results}

The number and scaling of earthquake records, imply that 500 nonlinear dynamic runs were carried out for each model. The IDA results, shown in Figure 9, indicate the $S_{a}\left(T_{1}\right)$ versus MIDR values for each scaling of individual records (grey circles). These can be further summarised into 
the $16^{\text {th }}, 50^{\text {th }}$ (median) and $84^{\text {th }}$ fractile IDA curves by estimating the respective percentile given the range of $S_{a}\left(T_{1}\right)$ values.
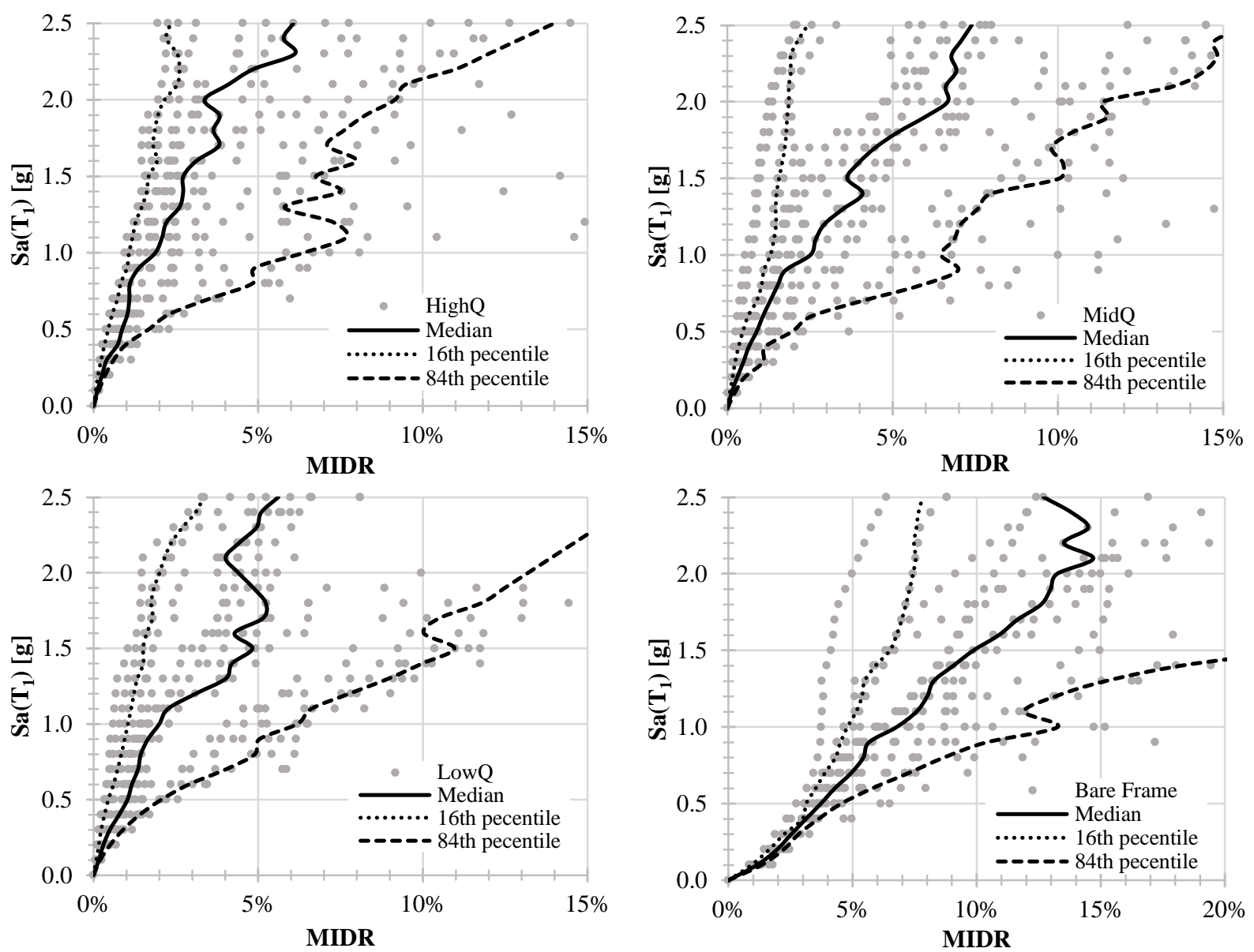

Figure 9 - Incremental Dynamic Analysis (IDA) results in terms of Maximum Peak Inter-storey Drift Ratio (MIDR) for different construction qualities and bare steel frame

As expected, for a certain $S_{a}\left(T_{1}\right)$ applied, the bare steel frame undergoes a larger deformation compared to the stiffer cases with infill panel. This increase in deformation can also be observed as the quality of structures and consequently its initial period drops. It should be noted that in some cases, due to the nature of the record, the structure fails at lower intensity measures and the model is not capable of fulfilling the entire range (i.e. up to $2.5 \mathrm{~g}$ ). For instance, this condition is more evident for Low Quality model, in which after an intensity of $1.8 \mathrm{~g}$, the collapse stage is reached for most of the applied earthquakes and therefore no data on structural drift is recorded.

\section{Fragility Curves}

Fragility functions are defined, in order to specify the probability of any defined damage limit state of a structure in terms of some ground motion intensity measure (IM). Adopting the recorded structural response of IDA, the analytical fragility functions for each of the considered models are derived. Since there are no directivity-influenced records in the earthquake suite and all selected buildings are of medium height (i.e. first-mode-dominated), to characterise the intensity of earthquakes, the spectral pseudo-acceleration corresponding to the first-mode elastic 
vibration period and 5\% damping ratio is chosen. Furthermore, as previously mentioned, maximum peak inter-story drift ratio has been used as the engineering demand parameter (EDP).

Each ground motion has been scaled to increasing levels of intensity until collapse stage is reached, indicated by achieving large inter-story drift values. This process has been repeated for a set of 20 records to characterise the empirical distribution of seismic demand (i.e. performance points). By fitting a parametric model to the obtained data, fragility functions have been derived. To observe the variance caused by using different fitting techniques, three common ones have been compared. Maximum Likelihood (Shinozuka et al., 2000), Least Square method (Baker, 2015) and Generalised Linear Regression method (GLM) with clog-log link function (Basöz \& Kiremidjian, 1998) have been applied (see Figure 10). A thorough discussion on the mentioned statistical procedures for developing fragility function fitting can be found in lallemant et al. (2015) and Baker (2015). Comparing the resultant fragility functions indicates that due to high number of performance points, all three fitting methods result in similar curves and are enclosed by the confidence intervals.

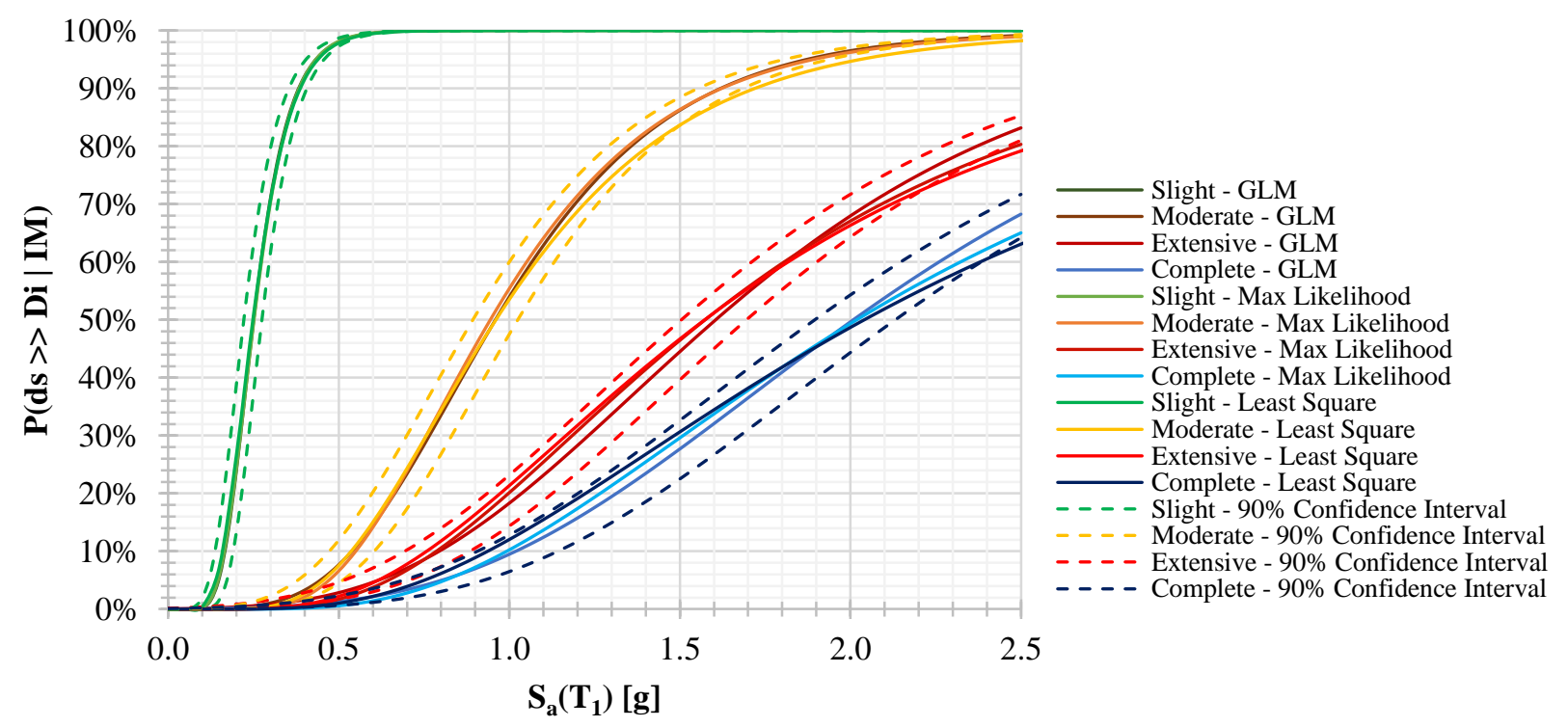

Figure 10 - Comparing different fragility fitting functions for Model 1 - High Quality

A least square regression is used, in which Median $(\mu)$ and Dispersion ( $\beta$ ) (i.e. standard deviation of $\ln (I M))$ parameters are estimated in a way to minimise the sum of squared errors (SSE) between the probabilities predicted by the fragility function and the fractions observed from the data.

$$
\mu, \beta=\operatorname{argmin}_{\mu, \beta} \sum_{i=1}^{m}\left(\left(\frac{z_{i}}{n_{i}}\right)-\Phi\left(\frac{\ln \left(x_{i} / \mu\right.}{\beta}\right)\right)^{2}
$$

where, $m$ is the number of IM levels, ${ }_{i} / n_{i}$ is the observed ratio of any building passing a certain damage state at $\mathrm{IM}=x_{i}, \Phi()$ is the standard normal cumulative distribution function (CDF). Following this fitting techniques, the fragility curves obtained for each of the models, while considering the variation in seismic demand and modelling parameters, are presented in Figure 11. 

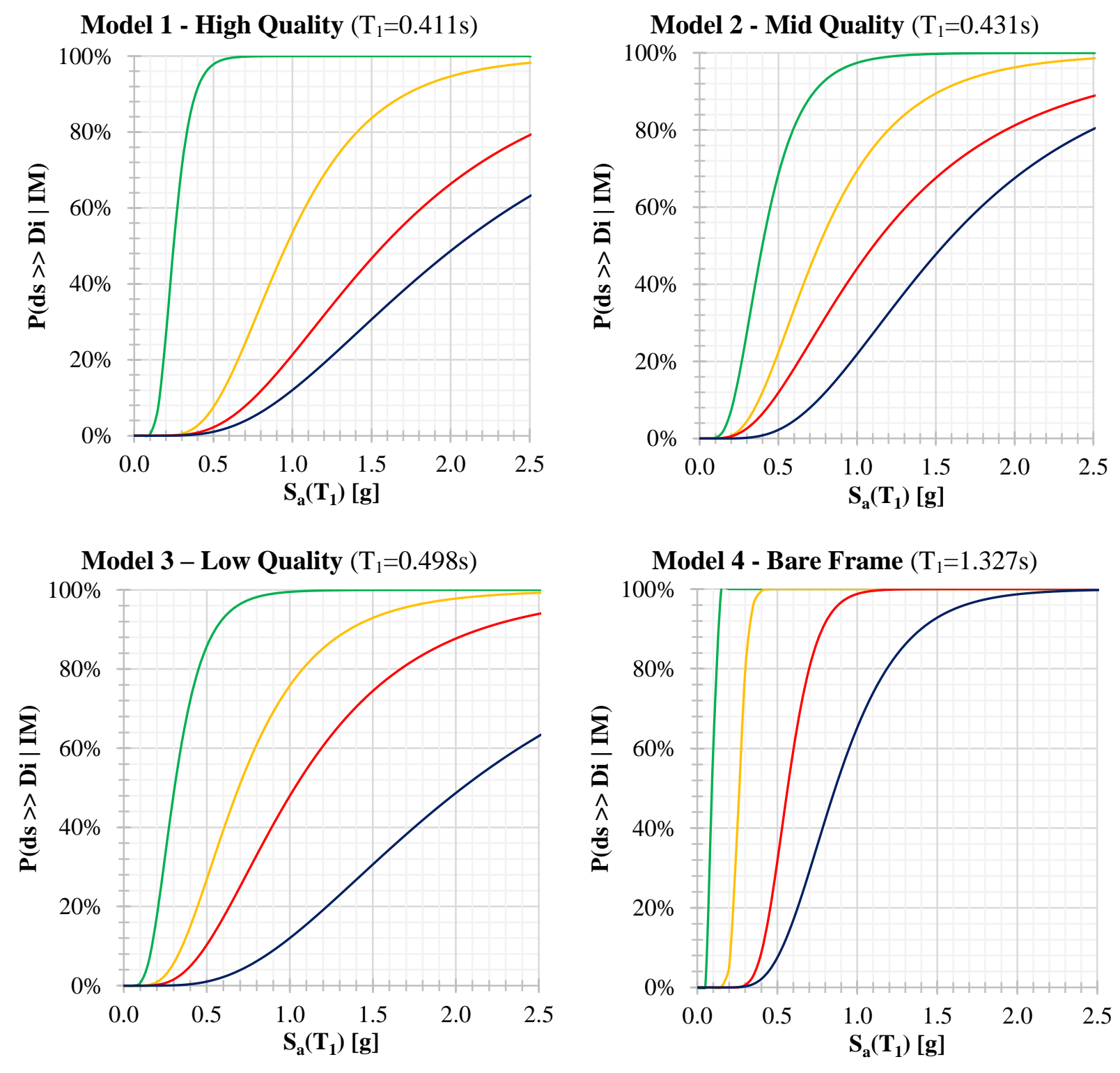

- Slight $\quad$ Moderate Extensive Complete

Figure 11 - Fragility curves derived for each model

The median and dispersion values for each of the obtained fragility curves are given in Table 4 .

Table 4 - Median $(\mu)$ and Dispersion $(\beta)$ values for the fragility curves

\begin{tabular}{ccccccccc}
\hline \multirow{2}{*}{$\begin{array}{c}\text { Damage } \\
\text { State }\end{array}$} & \multicolumn{2}{c}{$\begin{array}{c}\text { Model 1 } \\
\text { High Quality }\end{array}$} & \multicolumn{2}{c}{$\begin{array}{c}\text { Model 2 } \\
\text { Mid Quality }\end{array}$} & \multicolumn{2}{c}{$\begin{array}{c}\text { Model 3 } \\
\text { Low Quality }\end{array}$} & \multicolumn{2}{c}{$\begin{array}{c}\text { Model 4 } \\
\text { Bare Frame }\end{array}$} \\
\cline { 2 - 9 } & $\mu$ & $\beta$ & $\mu$ & $\beta$ & $\mu$ & $\beta$ & $\mu$ & $\beta$ \\
\hline Slight & 0.248 & 0.347 & 0.397 & 0.473 & 0.305 & 0.461 & 0.097 & 0.141 \\
Moderate & 0.961 & 0.455 & 0.756 & 0.545 & 0.691 & 0.527 & 0.261 & 0.167 \\
Extensive & 1.573 & 0.570 & 1.104 & 0.671 & 1.030 & 0.572 & 0.565 & 0.253 \\
Collapse & 2.040 & 0.607 & 1.548 & 0.563 & 1.423 & 0.601 & 0.862 & 0.378 \\
\hline
\end{tabular}




\section{Vulnerability ASSESSMENT}

Due to the essence of the derived fragility functions, the seismic hazard of the location under study (coordinate $35^{\circ} 39^{\prime} \mathrm{N} 50^{\circ} 54^{\prime} \mathrm{E}$ ), should be considered in terms of spectral acceleration $\left(\mathrm{S}_{\mathrm{a}}\left(\mathrm{T}_{1}\right)\right)$. Following the intensity-based assessment approach, the spectral acceleration values, corresponding to $10 \%$ probability of exceedance in 50 years life time of the structures are

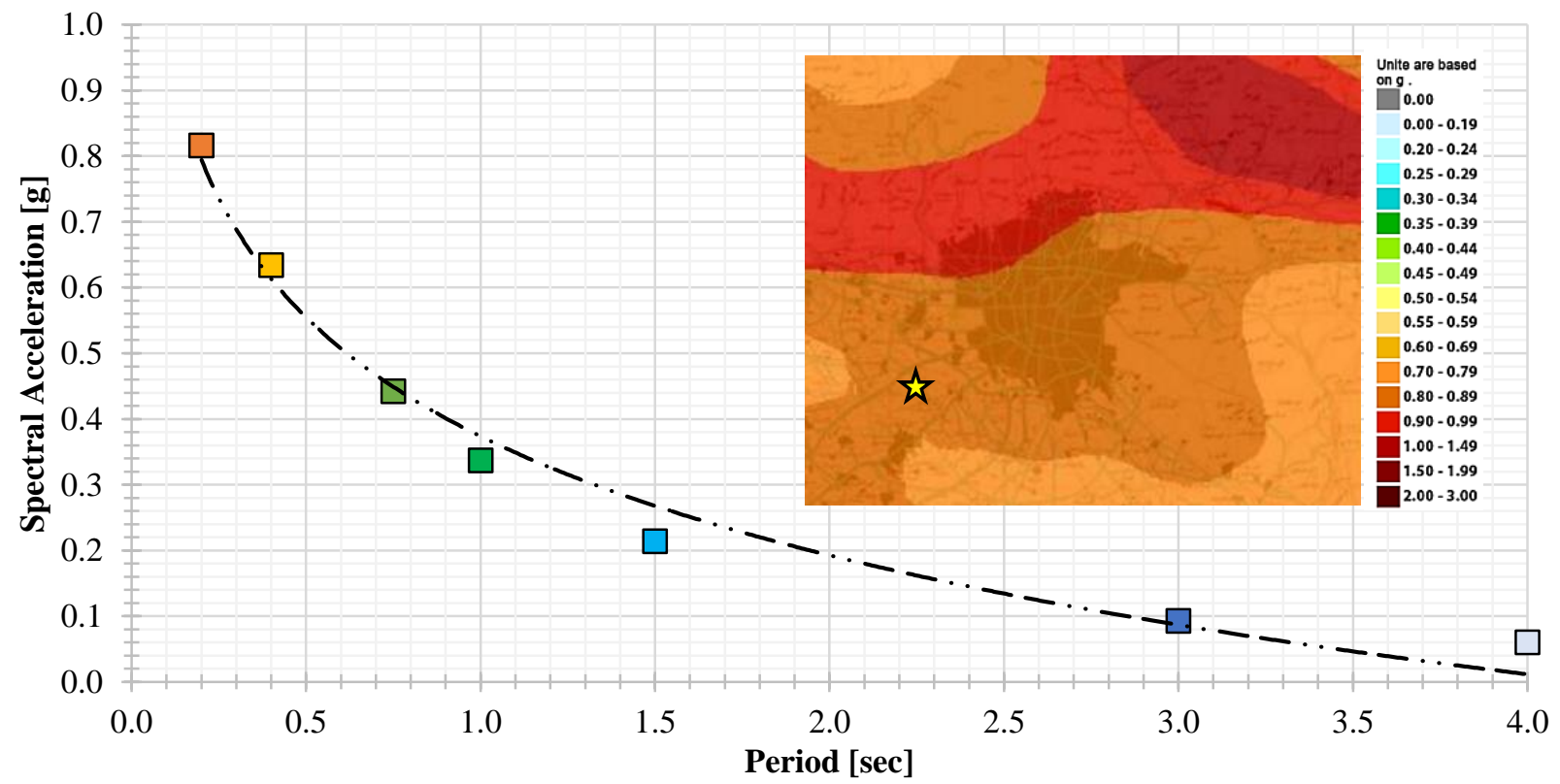

derived for each of the buildings (see Figure 12).

Figure 12 - Spectral acceleration corresponding to various periods.

The seismic hazard map corresponds to a period of 0.2 seconds for an earthquake with $10 \%$ probability of exceedance within 50 years life time of structure on Soft Rock $\left(\mathrm{V}_{\mathrm{S} 30}=525 \mathrm{~m} / \mathrm{s}\right)$

(Seismic Hazard Analysis of Tehran, 2008)

In order to quantify the vulnerability of the location under study, the distribution of each building model has been accounted by considering three case. The distribution according to experts' opinion, is based on the building cases currently under construction, similar to the selected index building. Hence, the qualitative and quantitative distribution of existing structures have not been considered. While, the conservative distribution case, considers the possible distribution of all existing buildings and accordingly includes higher percentage of buildings with lower quality. For comparison reasons, a case with equal distribution is also studied. The mentioned distributions are presented in the following charts (Figure 13).

\section{Expert Opinion $\quad$ Equal Distribution $\quad$ Conservative Case}




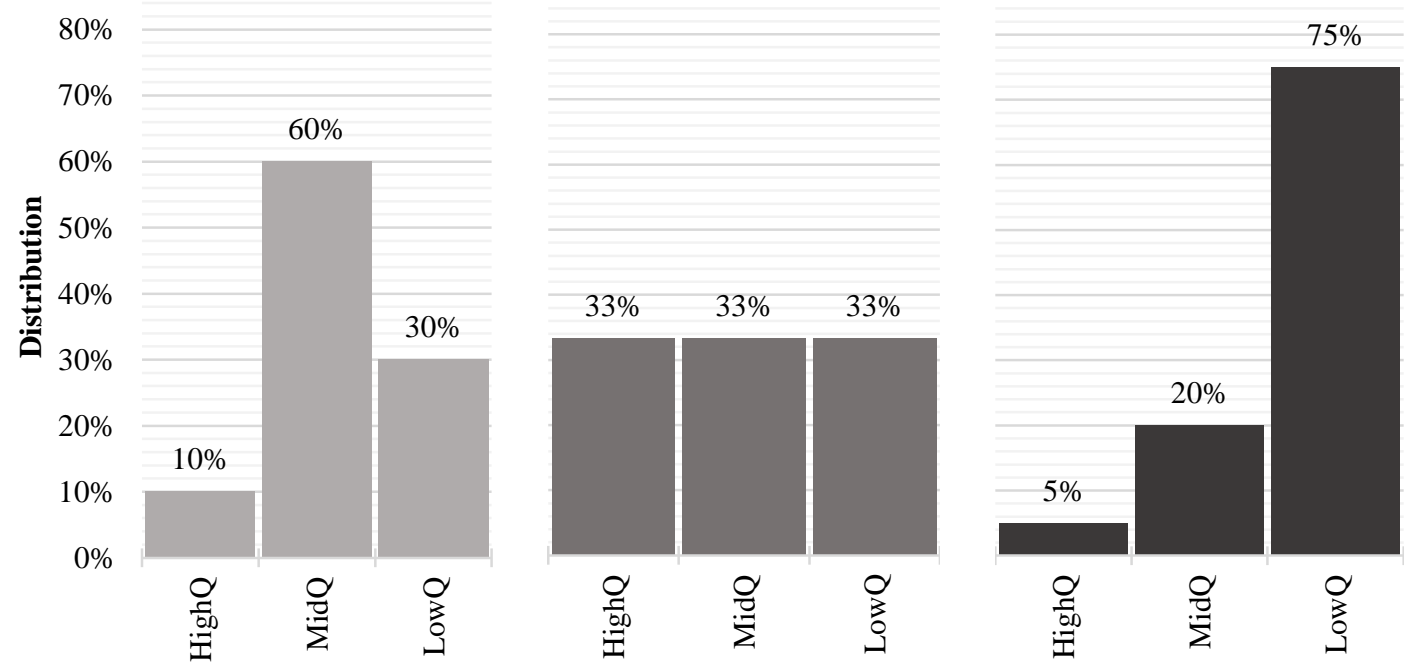

Figure 13 - Cases considered for different building distribution

Cost ratios are used to represent damage as a proportion of total construction replacement cost. In this study, the values suggested by Risk-UE (Mouroux \& Le Brun, 2006) have been implemented and the repair cost for each of the buildings have been obtained accordingly. The total cost of constructing the buildings has been estimated as $£ 150$ per metre squared, regardless of the building's quality. Comparing the bare steel frame and the highest quality model, a considerable difference is observed, as the repair cost is about 1.7 times higher (Figure 14). This is an important issue for disaster management and insurance coverage.

Considering thousand structures and applying the mentioned distribution cases, the total structural losses for an earthquake with 475 year return period is calculated and compared in Figure 15. As expected, due to higher distribution of low quality structures in the conservative case, the total structural loss obtained for this case has a higher estimation than the other two cases. The cost of repair and consequently the total losses estimated for the bare steel frame can be used as a bench mark, indicating the importance of realistic simulation.

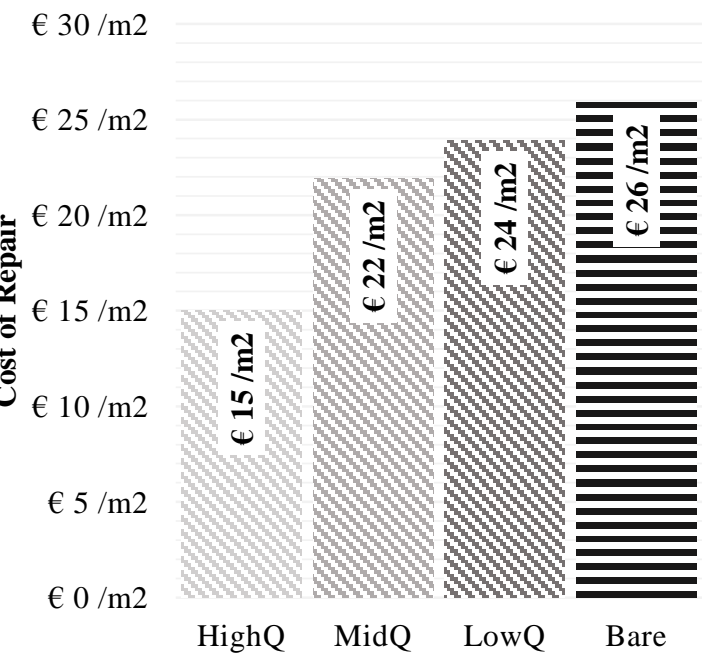

Figure 14 - Cost of Repair of different qualities of construction (earthquake with 475 year return period)

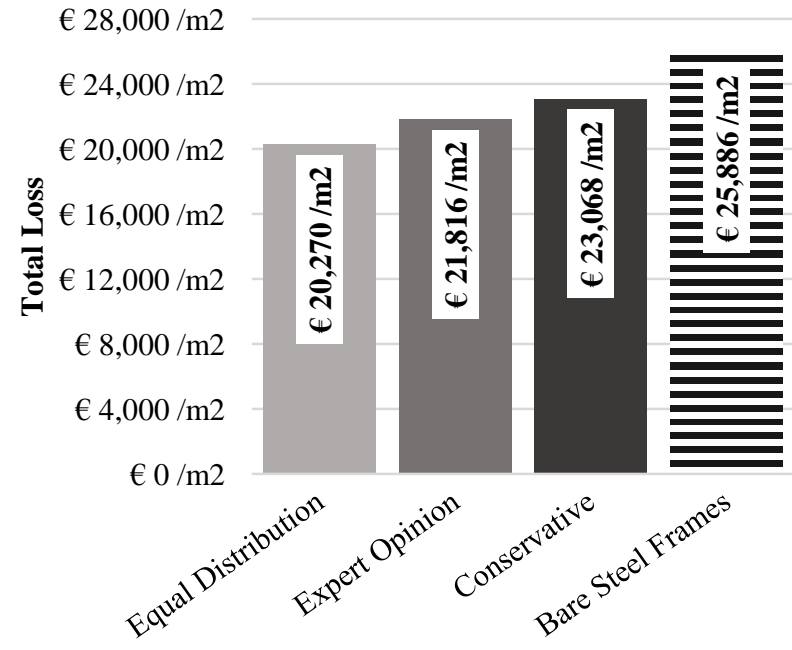

Figure 15 - Total Loss of a thousand building units (earthquake with 475 year return period) 
A detailed breakdown of structural loss, considered for thousand buildings with different qualities and structural distribution is illustrated in Figure 16. Referring to the observed variation, it can be concluded that realistic knowledge of exposure and structural behaviour is vital in seismic loss estimation.

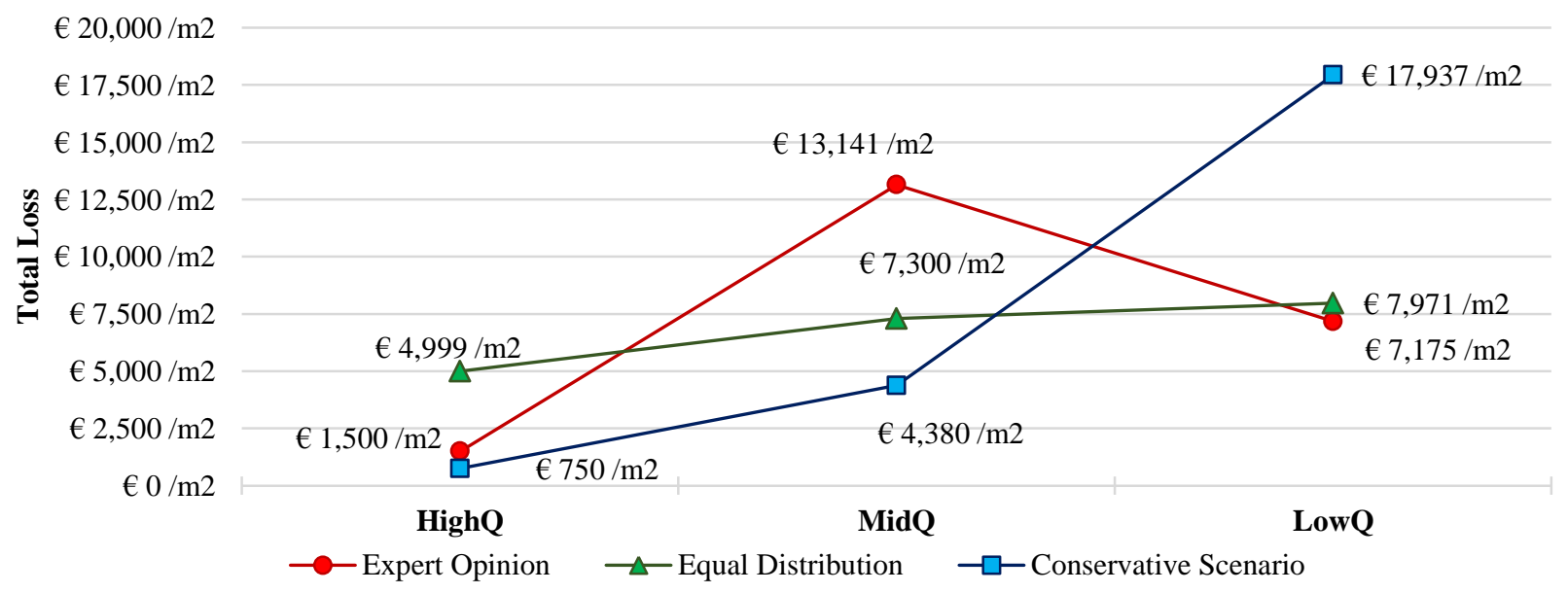

Figure 16 - Loss Estimation for different distribution cases of a thousand building units for an earthquake with 475 year return period.

\section{CONCLuSion}

The vulnerability of a masonry infilled steel frame structures with three different construction qualities have been assessed under seismic excitation. The selected index building is an acceptable representative of mid-rise masonry infilled steel frame buildings currently being constructed in seismically active parts of the world, especially the middle-east. Different seismic performances have been simulated by altering the three critical parameters (connection types, masonry infill material, contribution of bracings to seismic resistance). The correlation between variation in simulating the construction details and the structural response has been quantified by means of incremental dynamic analysis (IDA). Spectral acceleration for the initial period $\left(\mathrm{S}_{\mathrm{a}}\left(\mathrm{T}_{1}\right)\right)$ and maximum peak inter-storey drift ratio (MIDR) have been adopted for seismic performance evaluation of the selected buildings. The fragility curve of each model has been derived by employing a least square fitting technique. Considering an intensity based assessment approach and three different building distributions, the vulnerability of each case has been estimated. The total losses were estimated following the intensity-based performance assessment approach for an earthquake with $10 \%$ probability of exceedance in 50 years life time of the building. As expected, the structures with lower construction qualities had a considerable influence on the final monetary loss estimations. The obtained results indicate the significant influence of detailing in modelling and realistic knowledge of exposure, on the estimated of losses.

\section{REFERENCES}

ASCE/SEI 41-13, (2013) Seismic Evaluation and Retrofit of Existing Buildings, American Society of Civil Engineers, Reston, Virginia - United States of America.

Baker, J.W., \& Cornell, C.A., (2006) Spectral shape, epsilon and record selection, Vol. 35, Issue 9, pp.1077-1095. 
Baker, J.W., (2015) Efficient analytical fragility function fitting using dynamic structural analysis, Earthquake Spectra, 31(1), pp. 579-599.

Basöz, N., \& Kiremidjian, A.S., (1998) Evaluation of Bridge Damage Data from the Loma Prieta and Northridge, CA Earthquakes, Technical Report MCEER-98-0004, Multidisciplinary Centre for Earthquake Engineering Research, Buffalo, New York.

Bazzurro, P., \& Luco, N., (2007) Effects of different sources of uncertainty and correlation on earthquake-generated losses, Australian Journal of Civil Engineering, Vol. 4, No. 1, pp. 1-14.

El-Dakhakhni, W.W., Elgaaly, M., \& Hamid, A.A., (2003) Three-Strut Model for Concrete Masonry-Infilled Steel Frames, Journal of Structural Engineering, Vol. 129, Issue 2, pp. 177-185.

Ellul, F., \& D’Ayala, D., (2012) Realistic FE Models to Enable Push-Over Non Linear Analysis of Masonry Infilled Frames, The Open Construction and Building Technology Journal, 6, (Suppl 1-M14), pp. 213-235.

FEMA 356, (2000) Prestandard and commentary for the seismic rehabilitation of buildings, Federal Emergency Management Agency, Washington, D.C.

FEMA P-58, (2012) Seismic Performance Assessment of Buildings Volume 1-Methodology, Federal Emergency Management Agency, Washington, D.C.

FEMA P695, (2009) Quantification of Building Seismic Performance Factors, Federal Emergency Management Agency, Washington, D.C.

Flanagan, R.D., \& Bennett, R.M., (1999) In-Plane behaviour of structural clay tile infilled frames, Journal of Structural Engineering, 125(6), pp. 590-599.

Hazus - MH MR5, (2013) Advanced Engineering Building Module (AEBM) - Technical and User's Manual, Washington D.C.: Federal Emergency Management Agency.

Lallemant, D., Kiremidjian, A., Burton, H., (2015) Statistical procedures for developing earthquake damage fragility curves, Earthquake Engineering \& Structural Dynamics, Vol.44, Issue 9, pp. 1373-1389.

Leon, R.T., \& Deierlein, G., (1996) Considerations for the use of quasi-static testing, Earthquake Spectra, Vol.12, No.1, pp. 87109.

Luco, N., \& Bazzurro, P., (2007) Does amplitude scaling of ground motion records result in biased nonlinear structural drift responses?, Earthquake Engineering \& Structural Dynamics, Special Issue: Seismic Reliability Analysis of Structures, Volume 36, Issue 13, pp. 1813-1835.

Menegotto, M., \& Pinto, P. E., (1973) Method of analysis for cyclically loaded RC plane fames including changes in geometry and non-elastic behaviour of elements under combined normal force and bending, Proc., IABSE Symp. on the Resistance and Ultimate Deformability of Structures Acted on by Well Defined Repeated Loads, Preliminary Rep., Lisbon, Portugal, 15-22.

Mouroux, P., \& Le Brun, B., (2006) RISK-UE An advanced approach to earthquake risk scenarios with applications to different European town”, Final Report. European Commission, Brussels.

Nassirpour, A., \& D’Ayala, D., (2014) Fragility Analysis of Mid-Rise Masonry InFilled Steel Frame (MISF) Structures, Second European Conference on Earthquake Engineering and Seismology, Istanbul, Turkey.

Seismosoft, (2013) SeismoStruct v7.0, a computer program for static and dynamic nonlinear analysis of framed structures, available from: www.seismosoft.com.

Shinozuka, M., Feng, M.Q., Kim, H.K., Kim, S.H., (2000) Nonlinear Static Procedure for Fragility Curve Development, ASCE Journal of Engineering Mechanics, Vol.126, No.12, pp. 1267-1295.

Shome, N., Cornell, C.A., Bazzurro, P., Carballo, J.E., (1998) Earthquakes, Records, and Nonlinear Responses. Earthquake Spectra, Vol. 14, No. 3, pp. 469-500.

Tasnimi, A., \& Mohebkhah, A., (2011) Investigation on the behaviour of brick-infilled steel frames with openings, experimental and analytical approaches, Engineering Structures, Vol.33, Issue 3, pp.968-980.

Vamvatsikos, D., \& Cornell, C.A., (2002) Incremental dynamic analysis, Earthquake Engineering and Structural Dynamics, Vol. 31, Issue 3, pp. 491-514. 